\title{
Stabilisation agriculture: reviewing an emerging concept with case studies from Afghanistan and Iraq
}

\author{
by Adam-Bradford, A., El-Kahlout, G., Byrne, R., \\ Wright, J. and Rahman, M.
}

Copyright, publisher and additional information This is the published manuscript which is also available via CAB Direct.

Please refer to any applicable terms of use of the publisher.

DOI: $\underline{10.1079 / P A V S N N R 202015042}$

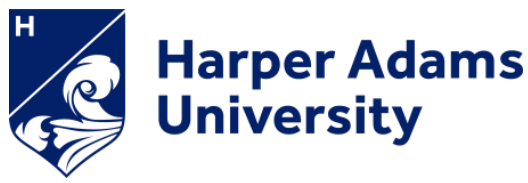




\title{
Stabilisation agriculture: reviewing an emerging concept with case studies from Afghanistan and Iraq
}

\author{
Andrew Adam-Bradford ${ }^{1 *}$, Ghassan Elkahlout ${ }^{2}$, Richard Byrne ${ }^{3}$, Julia Wright ${ }^{1}$ and Mohammed \\ Rahman $^{4}$
}

Address: 'Centre for Agroecology, Water and Resilience (CAWR), Coventry University, Coventry, UK.

${ }^{2}$ Conflict Management and Humanitarian Action Programme, Doha Institute for Graduate Studies, Doha, Qatar.

${ }^{3}$ Rural Security Research Group, Harper Adams University, Newport, UK.

${ }^{4}$ Human Relief Foundation, Bradford, UK.

ORCID information: Andrew Adam-Bradford (orcid: 0000-000 I-8530-56IX); Ghassan Elkahlout (orcid: 0000-000 I-84I0-4322);

Richard Byrne (orcid: 0000-0003-3489-0470); Julia Wright (orcid: 0000-0003-0330-8257)

*Correspondence: Andrew Adam-Bradford. Email: andrewadambradford@gmail.com

$\begin{array}{ll}\text { Received: } & 06 \text { November } 2019 \\ \text { Accepted: } & \text { 05 June } 2020\end{array}$

doi: 10.1079/PAVSNNR202015042

The electronic version of this article is the definitive one. It is located here: http://www.cabi.org/cabreviews

(c) CAB International 2020 (Online ISSN 1749-8848)

\begin{abstract}
Stabilisation Agriculture has been defined as a focus on enhancing the ecological and social resilience of agricultural communities to withstand and respond to adverse conditions in countries affected by disasters, ranging from climate events to conflict and complex emergencies. However, in this review paper, rather than taking a broad disaster risk management approach to the topic, a focus is made on the nexus between agriculture, food security and conflict. Food insecurity, for example, can trigger instability and conflict, leading to the collapse of agricultural infrastructure, the loss of farm labour, and local farming knowledge through loss of life and forced migration. This cycle becomes endemic and reinforcing, often resulting in chronic food shortages and eventually conflict-driven famine. Hence, why an emphasis on post-conflict "stabilisation" is made in this examination of the emerging concept of Stabilisation Agriculture. Case studies from Afghanistan and Iraq are used to illustrate the benefits of elevating agriculture as a critical response tool in post-conflict and stabilisation settings, and following a subsequent discussion that explores the critical synergies in this emerging field, a redefined definition of Stabilisation Agriculture is proposed along with recommendations for future development through policy inclusion and mainstreaming, post-conflict programming and applied research.
\end{abstract}

Keywords: food security, post-conflict, resilience, stabilisation agriculture, stabilisation

\begin{abstract}
Review methodology: The review on stabilisation theory was based on a desk-based study of policy material from several donor government agencies, including Denmark, the UK, and the USA. The review of the current definitions of Stabilisation Agriculture was conducted through an examination of books and professional magazines addressing the interface of agriculture and conflict and an examination of recent Stabilisation Agriculture promotional materials from Coventry University. For the Afghanistan case study, the review of the Provincial Reconstruction Team (PRT) and the British Army's CIMIC (Civil-Military Cooperation) unit's activities is drawn from the third author's participation in these activities, in Afghanistan and in the UK delivering training and support to deployed personnel (20082012). This work culminated in a multinational "lessons-learnt" exercise in 2014. All Afghanistan material is open source and reflects the authors' viewpoints and not that of the organisations involved. For the Iraq case study, the final technical reports of three UNDP-funded Stabilisation Agriculture project reports were reviewed. All the Iraq material is open source (available online at Human Relief Foundation) and again reflects the authors' viewpoints and not that of the organisations involved. In terms of community engagement and the data collection tools used in Afghanistan and Iraq, these are briefly discussed in each case study, but in both cases they clearly form components of the respective implementing agencies' rapid need assessment tool kits, as opposed to in-depth participatory research tools.
\end{abstract}

\section{Introduction}

Stabilisation Agriculture has been defined as a focus on enhancing the ecological and social resilience of agricultural communities to withstand and respond to adverse conditions in countries affected by disasters, ranging from climate events to conflict and complex emergencies [I]. The term "agricultural communities" is used to refer to 
people engaged in the production, processing and distribution of food, medicine, fuel and fibre through the cultivation of plants and livestock husbandry in both urban and rural settings. In a pre-disaster phase, for example, sustainable agricultural interventions, such as agroecology and/or agroforestry, can be used as a land management tool in disaster risk reduction (DRR) programmes, whilst in the post-disaster phase, the principle aim of Stabilisation Agriculture is the swift re-establishment of primary food production systems that are more resilient than previous systems [2]. In this context, resilience goes beyond the "field" and applies equally across social perspectives, permeating into areas such as social cohesion and peacebuilding, particularly in fragile geographical areas beset by violence and conflict.As Rohwerder [3] highlights there is a "need for more research into the impact of conflict, protracted crises and disasters caused by natural hazards on agriculture and especially into the effectiveness of different efforts to support and rebuild agriculture". These issues are some of the themes that will be explored in this review paper that aims to examine the emerging concept of Stabilisation Agriculture. The paper includes a brief introduction to stabilisation theory along with an explanation of the current definitions of Stabilisation Agriculture. This will be followed by the presentation of two case studies, the first is from a UK Governmentfunded stabilisation programme in Afghanistan, and the second is from three UNDP-funded Stabilisation Agriculture projects in Iraq. Following a subsequent discussion that explores the critical synergies in this emerging field, a redefined definition of Stabilisation Agriculture is proposed along with recommendations for future development through policy inclusion and mainstreaming, post-conflict programming and applied research.

\section{Stabilisation: from a theory to action}

Over the last decade, the concept and approach of using "stabilisation" as a mechanism to respond to violent conflicts in an attempt to re-establish security and prepare for longer-term recovery have been substantially developed. Stabilisation has been fully incorporated by several donor government agencies, which include the UK's cross-government Stabilisation Unit; USAID's Bureau for Conflict Prevention and Stabilisation (CPS) and Denmark's Peace and Stabilisation Fund (PSF) headed by its own Inter-Governmental Steering Committee (IGSC). Likewise, stabilisation programming has also been fully integrated by UN agencies, particularly by the United Nations Development Programme (UNDP), which currently has stabilisation programmes in Iraq, Libya, Nigeria and Yemen [4].

In essence, these stabilisation approaches are quite similar. For example, in the UK context, stabilisation is defined as "an activity undertaken as an initial response to violence or the immediate threat of violence" ([5], p. I3). In the US context, the aim of the CPS is to "strengthen USAID's capacity to prevent conflict, address fragility, respond to global crises in a more strategic, integrated way, and act as a stabilizing force in times of transition" ([6], p. I). Denmark also deploys a flexible instrument, through the use of its PSF, which is an inter-ministerial fund with the objective to support efforts at the interface between security and development [7]. Likewise, the UK government's objective through stabilisation interventions is to "support local and regional partners in conflictaffected countries to reduce violence, ensure basic security and facilitate peaceful political deal-making, all of which should aim to provide a foundation for building long-term stability" ([5], p. II). To enact this, it employs three central stabilisation principles:

I. protecting the means of survival;

2. promoting and supporting a political process to reduce violence and

3. preparing a foundation for longer-term stability.

The first principle addresses any immediate security concerns, thus building opportunities that allow peaceful political processes that in time support the restoration of long-term stability. The second principle ensures stabilisation supports and fosters political deals and bargains amongst key conflict elites and actors. Ensuring that any pre-conflict situations that were inequitable and/or unsustainable are not repeated, but rather deeper and more resilient solutions are found that prepare a foundation for longer-term stability, the final stabilisation principle, which may range from months to years to achieve. It is also anticipated that shorter-term stabilisation interventions will be delivered simultaneously and will overlap with other approaches, such as DFID's Building Stability Framework or similar approaches from supporting partners and/or local governments. Finally, the UK government highlights the importance of incorporating a conflict-sensitive approach to ensure that a peace-building process is adopted, as well as a gender-sensitive approach, so that the linkages between gender and conflict are addressed, thus reducing the gender-based causes, and negative gender impacts, of conflict [5].

\section{Defining stabilisation agriculture}

"Stabilisation Agriculture" as an academic term was first coined by Prof. Phillip Harris from the Centre of Agroecology and Food Security (CAFS),' Coventry University in 2010 [2]. Interestingly back in 1961, and

\footnotetext{
'In 20I4, the Centre of Agroecology and Food Security (CAFS) merged with other research entities at Coventry University to become the Centre for Agroecology, Water and Resilience (CAWR).
} 
unbeknown to Prof. Harris, an Agricultural Stabilisation and Conservation Service (ASCS) was established in the USA and functioned up to 1994, with its remit including the stabilisation of farm income and conservation of the natural resource base that agriculture depends on, as reflected in the former US government agency's descriptive title. In many ways, these early resilience-based objectives were encapsulated in CAFS's [I] first definition of Stabilisation Agriculture, which:

focuses on enhancing the ecological and social resilience of agriculture to withstand and respond to adverse conditions in countries affected by natural and human-induced disasters, both pre- and post-disaster. The main components include:

- Re-establishing agriculture after human-induced or natural disasters

- Exploring sustainable agriculture and institutional engagement in "stabilisation" regions

- Sustainable management of abiotic stresses in agriculture, such as drought, salinity, contaminated land and climate change

- Sustainable management of biotic stresses in agriculture, such as invasive plant species, insect plagues.

With regard to re-establishing agriculture, emphasis is placed on the transition to a more "regenerative agriculture" approach, rather than a simple continuation of-or return to-the previous system, for example, implementing agroecology or an agroforestry-based system.Another key component is its operationalisation in identified "stabilisation regions", such as, at the time of writing, Libya, Somalia and Zimbabwe, or the two subsequent case studies:Afghanistan and Iraq.

These concepts were developed I year later in 201 I, when the Stabilisation Agriculture concept was formerly launched at an international workshop in London, jointly organised by the Centre for Peace and Reconciliation Studies $^{2}$ (CPRS) and the Centre for Agroecology and Food Security (CAFS), both at Coventry University. The ambitious aim of the workshop was to "define a shared understanding of agriculture in the context of stabilisation after natural and man-made disasters, to identify best practice and constraints, and to develop an agenda for research and policy development with the aim of improving interventions" ([8], p. I). Interestingly, one of the key findings of the workshop was "that despite the importance of sustainable agriculture in such challenging environments, little has been published to date on the subject" ([8], p. I).

Following the workshop, an attempt to reverse this trend was attempted with the publication of an edited volume from Özerdem and Roberts [8] entitled "Challenging Post-conflict Environments: Sustainable Agriculture”. This

${ }^{2}$ The Centre for Peace and Reconciliation Studies (CPRS) is now known as Centre for Trust, Peace and Social Relations (CTPSR). comprehensive collection of papers included conflictrelated case studies from Afghanistan [9], Cambodia [10], Indonesia [II], Lebanon [12], Nepal [13], Sri Lanka [14], Sierra Leone [15-17] and Sudan [18]. More conventional agricultural research related to agriculture, development and sustainability was also included in the volume [8]. Separate from this, and 2 years later, another edited volume was published, this time by Tidball and Krasny [19] entitled "Greening in the Red Zone: Disaster, Resilience and Community Greening”. Although there was no reference made to Özerdem and Roberts [8], the work of Tidball and Krasny [19] encapsulated some of previous principles of Stabilisation Agriculture but through a different lens and with distinct and unique terminology. For example, they started with their own concept of "greening", which was defined as:

an active and integrated approach to the appreciation, stewardship and management of living elements of social-ecological systems. Greening takes place in cities, towns, townships and informal settlements in urban and peri-urban areas, and in the battle fields of war and disaster ([20], p. 7).

In this definition, the battle fields were the red zone, defined as:

multiple settings (spatial and temporal) that may be characterized as intense, potentially or recently hostile or dangerous, including those in post-disaster situations caused by natural disasters such as hurricanes and earthquakes, as well as those associated with terrorist attacks and war ([20], p. 8).

From a Stabilisation Agriculture perspective, this volume included some relevant case studies from Afghanistan [2I, 22], Bosnia-Herzegovina [23], Cameroon [24], Japan [25] and Liberia [26], although throughout the volume there was no mention of "stabilisation" from either a post-conflict or a post-disaster context. It was not until 2016 that the term gained increased traction following the United Nations Development Programme (UNDP) funding of a pilot Stabilisation Agriculture project in Iraq (see Section "Stabilisation Agriculture Programmes in Salah Al-Din Governorate, Iraq"). In the same year, the definition was developed by CAWR [27] and appeared in a promotional pamphlet and was also published in a book chapter ([2], p. 73). These modifications consisted of the four main components of Stabilisation Agriculture being slightly modified and extended, thus becoming six components, and including for the first time aspects of forced displacement, such as working with urban agriculture in displacement camps ${ }^{3}$ and in cities where numerous dispersed refugees or distinct pockets of refugee populations can be found:

\footnotetext{
${ }^{3}$ Includes refugee camps as well as camps for internally displaced persons (IDPs), otherwise known as IDP camps.
} 
I. integrating and mainstreaming agroecology through programmes, policies and institutions, for disaster risk reduction (DRR);

2. agroecology for refugee camps and settlements;

3. urban agriculture for dispersed refugees and host communities in urban areas;

4. facilitating transitions: (i) food aid to food production; (ii) refugees to returnees and (iii) combatants to farmers; 5. sustainable management of abiotic stresses in agriculture, such as drought, salinity, contaminated land and climate change and

6. sustainable management of biotic stresses in agriculture, such as invasive plant species and insect plagues.

This inclusion of urban agriculture and displacement camps stemmed from humanitarian operations and applied research work that featured in a special edition of Urban Agriculture Magazine [28], which included a range of emergency refugee camp and urban food security-related case studies with examples from Ethiopia [29], Indonesia [30], Iraq [3 I], Jordan [32], Kenya [33, 34], Liberia [35], Sierra Leone [36], Uganda [37, 38] and Zimbabwe [39].

More recently in Iraq and Jordan, the role of urban agriculture in displacement camps has been further investigated [40], with research findings highlighting the multiple benefits, for example, the importance of space for both personal peace and wellbeing, fresh food, trees and greenery, livelihood and daily practical activities and a contribution to building a sense of belonging, community and home [4I]. Likewise the actual challenges of incorporating urban agriculture into camp infrastructure have also been identified [42]. Other strands of this work have looked at some of the innovative aspects to urban agriculture including agroforestry [43], the role of wild edible plants [44] and sustainable drainage systems (SuDS) [45], and even the linkages to urban planning in times of crisis have been made [46].

In the most recent promotional materials from CAWR $[47,48]$, the main components of Stabilisation Agriculture have again been modified and currently reach a total of eight, whilst the introductory overview of the concept now includes references to the use of "agroecology-based practical processes" and "transdisciplinary knowledge systems" [47, 48]. At the same time, research emanating from this group is exploring the transformative potential of agroecology for peace building in fragile states [49]. As more rigorous case studies are developed and the peerreviewed evidence base is expanded, further modifications of the stabilisation definition will be made that strengthen the linkages between operational conditions on the ground and stabilisation theory.

\section{Practices of stabilisation agriculture}

Through examining the practices and circumstances of Stabilisation Agriculture, the concept and its understanding will continue to be developed. Case studies are thus relevant and useful to highlight the critical role that agriculture can play in post-conflict and stabilisation settings. In this section, the first case study provides an overview of the development of Stabilisation Agriculture in Helmand Province, Afghanistan, through a Civil Military Co-Operation (CIMIC) approach with the UK forces in Afghanistan and the Afghanistan Ministry of Agriculture of Irrigation and Livestock (MAIL). Then, the second case study examines three UNDP-funded Stabilisation Agriculture programmes implemented by the Human Relief Foundation (HRF) in Salah Al-Din Governorate, Iraq. Although both approaches substantially differ, each offers important lessons for the furtherance of this specific discipline.

\section{Development of stabilisation agriculture in Helmand Province, Afghanistan}

In 2008, the UK forces in Afghanistan began including agriculture within their Civil Military Co-Operation (CIMIC) activities, with the recognition that understanding, and including, agriculture was essential within their "Comprehensive Approach" and the emerging "Helmand Road Map" (a 2-year stabilisation plan). The inclusion of agriculture was at first seen as part of the promotion of "alternative or licit livelihoods" to counter widespread opium poppy growing, as it had become increasingly clear that there was a gap between the needs of counter narcotics operations and those of the civil-military community. The Provincial Reconstruction Team (PRT) based in Helmand Province was poorly resourced to consider agriculture, and its positioning under Counter Narcotics (CN) did little for the promotion of coherent livelihood strategies. Counter Narcotics was focused on eliminating opium poppy growing and then delivering licit agricultural livelihoods, but this approach did not necessarily create the conditions for a thriving agricultural economy to develop as an antithesis to the narcotic economy.

Indeed, the lack of coherence regarding how agriculture was to be promoted as a livelihood led to some initial setbacks. Efforts to promote agricultural development under the Counter Narcotics programme included a wheat seed and fertiliser distribution project that was launched in the autumn of 2008 and which had lasting negative impacts. The plan had been to promote wheat as an alternative crop by offering free seed and fertiliser to registered farmers in the Helmand Green Zone, the irrigated area bordering the river Helmand. This promotion was undertaken with little understanding of local cultural systems and caused profound disquiet amongst existing traders and suppliers as well as farmers who found themselves outside the scheme's boundaries. The message that farmers received was that some of them were more worthy of support from the Government and the PRT 
than others. It was furthermore unclear how much of the free fertiliser actually ended up on opium poppy production. As a PRT-driven exercise, it also lacked what the PRT termed (somewhat colonially) "the Afghan face", which was considered important in promoting the emerging Ministry of Agriculture of Irrigation and Livestock (MAIL). In late 2008, the PRT focus then shifted to developing markets though the construction of a new facility at Lashkar Gah, the provincial capital. The Lashkar Gah Bost Airport and Agriculture Centre would provide an outlet for new ventures to purchase and process goods from the surrounding towns and villages, ultimately for export. As a capital-intensive project lacking wider infrastructure and at some distance from the growing areas, this project was doomed to fail. Farmers chose not to travel into such an insecure area, preferring to sell their production locally or to buyers who came to them, thus alleviating them of transport problems. This latter concern was the real determinant for the farmer, as the risk encountered in accessing the market and returning through multiple check points where bribes were common place was a real disincentive to seek new markets. The risks from travelling to Lashkar Gah also included robbery and improvised explosive devices (IEDs) that had been set for security forces. Hence, the advantages of trading with merchants in cash now, even if the prices were lower, rather than travelling to Lashkar Gah with the prospect of greater return but at the risk of losing it to informal checkpoints or robbery.

Whilst the PRT focused on large "quick win" projects, the military returned to more nuanced activities, seeking to understand and influence farmers at ground level and to identify where Afghan Ministry of Agriculture staff could make real impact. The freedom of movement offered by the military made coverage of the Province from Garmsir in the south to Musa Qala in the north a reality. Most importantly, the military's work was tasked at the district level through an appointed "civilian stabilisation officer"4 who liaised with the local Governor in community engagement meetings (shuras) at the district levels. Through local meetings with farmers, market traders and others, participants' priorities were set. Work was divided into two core components: production and market. In the case of the market, the emphasis was placed on delivery of safe, secure spaces for markets to function. This included not only security guards but also the provision of solar lighting, waste removal processes and the slowing down of traffic. On the production side, the tasks revolved around a situation analysis ahead of the arrival of Afghan MAIL staff and identifying potential projects. Long-term projects included the rehabilitation of salinized soils and irrigation canals and the promotion of value adding through the

\footnotetext{
${ }^{4}$ Each battlegroup had a civilian stabilisation officer, appointed by the Foreign Office-Stabilisation Unit who held the rank equivalent to that of military battlegroup commander.
}

construction of grape drying houses. The actions were small, financially judicious and focused on farmer contact.

Measuring success was difficult in such circumstances, but observation of market activity indicated that small interventions were having a positive impact, for example, the re-use of cardboard boxes (previously burnt) for the transport of tomatoes, which had a small but significant impact on farmer incomes in that there was substantially less fresh produce wastage on the journey to market than transporting them in a sack as was done previously. By March 2009, awareness of the ability of agriculture to unite populations, influence political opinion and deliver economic benefit was clear. As commanders saw the value of recognising agriculture not as a method of countering narcotics but as the most appropriate means of reaching the population, kinetic activities were planned specifically to reduce impact on key agricultural infrastructure, and a wider reach for agricultural extension was sought. This came in the form of repurposing a radio broadcasting system-Radio In A Box (RIAB). Originally designed so the government could broadcast to the civilian population advice on military operations, Musa Qala District led the way by turning it over to a young Afghan DJ who broadcast music and interviews from around the town. Included in the content was a daily "agricultural feature" scripted by a member of the stabilisation team and translated into Pashto. Topics included fertiliser application, pesticide use and market updates. So whilst not promoting sustainable agriculture, these were widely listened to in the area, and within a few weeks, requests for features were being made.

The outcome of these actions was to positively reinforce the role and image of the local government and the MAIL staff and to deliver quickly across a range of geographies. This work built up over the next few years as more agriculturally trained staff were deployed who could identify, engage with contractors and monitor projects. Whilst the employment of (a less sustainable form of) Stabilisation Agriculture could never be claimed to have achieved peace, in pockets around Helmand, it helped establish the legitimacy of the government amongst key community members and opened a pathway for the Afghan MAIL staff to engage in wider agricultural development.

\section{Stabilisation agriculture programmes in Salah Al-Din Governorate, Iraq}

From 2015 to 20I7, the Human Relief Foundation (HRF), a British-based non-governmental organisation, implemented a series of short duration but high-impacting stabilisation interventions in Salah Al-Din Governorate region of Iraq, specifically in the conflict areas that had been recently retaken from the Islamic State (IS). As soon as the Iraq Government forces, with the US air support, had pushed IS out of previously held cities and towns, then at the earliest possible opportunity, stabilisation activities were implemented using a cash-for-work and cash-grant modality 
with funding from the UN Development Programme (UNDP). The primary objective of the programme was to contribute to immediate economic stabilisation through the provision of "cash injections" that were designed to stimulate livelihoods and start an initial process of economic activity.

In 20I5, the first stabilisation interventions were implemented in the city of Tikrit and thus consisted of urban-based activities. For example, the cash-for-work activities included painting over IS graffiti, rubble removal and street cleaning, and the small cash grants were issued to small businesses, such as bakeries, grocers and repair shops, so they could restock and start trading. Small cash grants were also made available for housing repairs, which also stimulated the market and supply chain for building materials [50]. Even the fighting-damaged campus of Tikrit University was cleaned-up with the use of HRF cash-forwork teams, which then led to the reopening of the University in December 2015 and the subsequent return of over 5000 students, thus accelerating the early recovery in the city of Tikrit [5I].

Following this early success in Tikrit, and as more territory was retaken from IS in SalahAl-Din Governorate, the emphasis of the programme changed from urbanbased activities to a programme designed around local agriculture, particularly as the geographical areas being retaken were becoming mainly rural settlements with predominantly agriculture-based livelihoods. This led, in 2016 and after a transitional period during the first phase, to a distinct shift to Stabilisation Agriculture interventions, with three programme interventions running in succession in the retaken district areas of $\mathrm{Al}$ Hajaj [52], Dhuluiyah [53] and Yathrib [54]. The first intervention with a duration of 3 months was in the district town Al Hajaj on the River Tigris, located south of the city Baiji. Following a need assessment, conducted through a "community platform" consisting of community leaders and members ([52], p. 2), the following conflictrelated linkages were made:

While the damage and destruction of buildings such as residential housing is less severe than in some other areas there has nevertheless been substantial impacts to local infrastructure and the natural resource base that underpins the livelihoods for many of the farmers that are resident in Al Hajaj District and its villages ([52], p. 2).

It was very evident that for local communities, the conflictrelated destruction was intricately linked to rural-based livelihoods, which was a distinct move from the earlier urban-based interventions. For example, problems stemmed from the construction of battle defences such as earth mounds using agricultural soils, thus damaging farmland surfaces and creating deep erosion:

and from the loss of electricity supply lines and transformers that provide the electricity to run the irrigation pumps. In addition, many of the farm lands are overgrown with weeds and shrubs and farmers no longer have access to suitable equipment, farm inputs (fertilisers/ seeds), tools and labour to prepare for the coming spring season. In regards to livestock, locally-constructed cowsheds and poultry farms have been damaged and restocking of livestock is also urgently required. In many of the villages there is debris and [rubble] is scattered around, with solid waste adding to the piles. The local authorities are unable to deliver any services such as debris removal and solid waste management. The residents of Al Hajaj District were in urgent need of assistance particularly to encourage returnees by providing an enabling environment that supported local food production with a focus of targeting the most vulnerable families in the District ([52], p. 2).

In AI Hajaj, Dhuluiyah and Yathrib, where the frontlines had been very fluid, landmines had not been laid by IS, although all the villages and farming areas were inspected for unexploded ordinances once they had been retaken. From the perspective of HRF (and, indirectly, the donor UNDP), the case for linking post-conflict stabilisation with agriculture was clearly made in the project rationale:

The project was required to provide immediate support for current residents which provided incentives and boosted the safe return of displaced families through the rehabilitation of livelihoods in the newly accessible areas of Al Hajaj District. Linking livelihood stabilisation and enterprise recovery provides the building blocks in long-term recovery and the building of a strong local economy which is also required to build social cohesion and minimise the impacts of the regional conflict as well as deterring extremism and sectarian-based violence which has clearly recently been evident in all areas of Salah Al-Din Governorate ([52], p. 3).

The practical activities were designed around seven different types of interventions:

I. preparation of agricultural lands;

2. repair of irrigation systems;

3. repair of livestock sheds;

4. restocking of livestock/bee keeping;

5. rubble removal;

6. street cleaning and solid waste management and 7. housing repairs.

Activities I-4 were designed specifically around agriculture and farm infrastructure, whilst the Activities 5-7 were a continuation of previous urban-based interventions but now aimed at clearing the rubble, debris and solid waste that had accumulated in the district town and surrounding villages of Al Hajaj District. In Activity I-the preparation of agricultural lands, a number of practical steps were taken following the assessment and prioritisation of farming plots. This first included the removal of weeds and shrubs through weeding and hoeing. An attempt was then made to introduce improved farming techniques through 
the introduction of bio-waste composting using compost windrows in the fields to produce compost from crop wastes and weeds. This was then followed by the tilling and raking of top soil and the provision of farm inputs to selected beneficiaries.All the practical work was conducted through the cash-for-work modality. Activity 2, repair of irrigation systems, comprised of two main components: (i) repair of the key transformers used to supply electricity to the irrigation pumps and (ii) repair of irrigation lines and pumps. The latter also involved the repairing of 3 mainline irrigation pumps (used to supply river water to the irrigation channels) and 55 on-farm irrigation pumps (used to pump water from the irrigation channels to the fields). In Activity 3-repair of livestock sheds, the shelters for both dairy cattle and poultry facilities were repaired, again using a cash-for-work modality. In Activity 4, the restocking of livestock/bee hives took place, with a total of 20 cows, 50,000 poultry and 20 fully-prepared bee hives being handed over to the farmers. All the livestock/bee hives were sourced from areas that had not been directly affected by the IS, with HRF procuring these stocks from livestock markets and bee suppliers.

The final project report [52] included a section "Lessons Learned", within which was two suggestions:(i) opportunities for the improvement in agricultural techniques and extension and (ii) potential for solar irrigation. Both these suggestions were aimed at making the conventional riverirrigated farming systems - that were located on the River Tigris-more resilient and climate smart:

\section{Improvement in agricultural techniques and extension}

The current stabilisation programmes are based on the provision of inputs through "financial inputs" as cash-forwork and "agricultural inputs". Both of these are forms of short duration stabilisation injections that provide an initial boost to upstart agricultural livelihoods, and return to previous farming systems. However, these systems are based on conventional agriculture that is dependent on chemical inputs such as fertilizers and pesticides. An effort should be made to make farmers more aware [of] organic and low-external-input-sustainable-agriculture (LEISA). This could take the form of: I) establishing demonstration farms; 2) on-farm-training; 3) capacity building of local agriculture offices and extension staff. Such activities could still be delivered during a stabilisation programme allowing for the delivery of improved technical services for local farmers ([52], p. 8).

\section{Solar irrigation}

The river-based farming systems in Iraq provide excellent conditions to establish solar-based irrigation systems. This would involve the replacing of conventional irrigation equipment (using electricity or diesel pump supplies) with solar-powered irrigation equipment to build resilient river-based farming systems. It is strongly recommended that a pilot solar irrigation is developed in Iraq. HRF have now held meetings with solar equipment suppliers and are developing a concept note ([52], p. 9).
Due to the successful implementation of the Stabilisation Agriculture project in Al Hajaj District, and although there was no formal project evaluation owing to the emergency nature of the interventions, a second project was planned for Dhuluiyah District. This followed a similar format and content as was implemented in Al Hajaj District, again with a 3-month duration, but with the additional activities of repairing 21 plastic polytunnels for horticulture, and rehabilitating "institutional buildings" that included school classrooms and the food storage warehouse at the Agriculture Directorate, the latter being very relevant in the context of local food security [53]. Following this Stabilisation Agriculture project in Dhuluiyah District, the next intervention was made in Yathrib District. Again this followed a similar format and content as the previous two projects but now with a 4-month duration, and instead of irrigation repairs, an irrigation sub-canal was constructed, and finally fruit trees, including pomegranate and apple, were added to the list of farm inputs being supplied to the beneficiaries. It is worth noting that the construction of the irrigation sub-canal had the primary aim of conflict resolution and only then a secondary aim of land reclamation for agricultural production. As previously, the Sunni communities had predominant access to the irrigation channels in the Yathrib District, but by extending the channels into new areas that are populated by Shia communities, this allowed improved access for all. Consequently, the project helped resolve a conflict across a traditional sectarian divide and thus allowed communities that were once forcibly displaced to return home, proving a clear example of the important role that agriculture can play in stabilisation and more specifically in peacebuilding.

\section{Integrating agriculture into stabilisation planning}

The linkages between agriculture and conflict have been clearly established in the edited volumes of Özerdem and Roberts [8] and Tidball and Krasny [19]. Food insecurity, for example, can trigger instability and conflict, leading to the collapse of agricultural infrastructure, the loss of farm labour and local farming knowledge through loss of life and forced migration. This cycle becomes endemic and reinforcing, often resulting in chronic food shortages and eventually conflict-driven famine. Climate change and any subsequent regional changes in rainfall variability only compound the complex and multifaceted nexus between agriculture, food security and conflict. Hence, why an initial advantage of adopting a Stabilisation Agriculture approach is that it elevates the important role that agriculture can play in post-conflict and stabilisation settings. This is clearly shown in the Helmand case study, when illicit agriculture and the production of opium funded the Taliban's conflict against the Afghan government.And this example of funding conflict from illicit land-based activities is not unique to Afghanistan, for example, in Somalia, a similar scenario has occurred but with illegal charcoal production, which has 
provided revenue for Al-Shabaab's conflict against the Somali government $[55,56]$.

Stabilisation Agriculture has a clear role to play in developing alternative and licit livelihoods, but this has to be achieved within the context of working towards a thriving agricultural economy, so that it results in an antithesis to narcotic or illegal economies. This also requires a good understanding of local issues that are facing farmers and of the political ecology that controls the exploitation of natural resources from local to international influences. Whilst improved security allows the development of agricultural-based economies, a thriving agricultural economy then reinforces the security through economic stabilisation, as demonstrated in the case study from the Salah Al-Din Governorate. Furthermore, when local extension services from the relevant ministries are fully integrated within the stabilisation approach, then this contributes to establishing the legitimacy of the government amongst local committees and key stakeholders, as in the case in Helmand, where it also opened the pathway for agricultural ministry staff to engage in wider agricultural development at the regional and local levels. In both case studies, local government played a clear role in community mobilisation and also the co-production of knowledge through the completion of need assessments that were often done under time pressures. In the post-conflict situation, participatory approaches are less effective as access, security and time all become critical obstacles to effective communication at the farm level.

Stabilisation Agriculture programmes can also stimulate livelihoods and provide immediate economic stabilisation through cash-based injections, using modalities such as cash for work and cash grants. However, these postconflict and stabilisation tools are, nevertheless, frequently used for more mundane post-conflict clear-up activities with the primary purpose of providing cash to vulnerable beneficiaries, allowing them to purchase food, water and other essential necessities. In contrast, funding Stabilisation Agriculture programmes contributes to a swifter reestablishment of primary food production systems, which in turn are required to build food security for both urban and rural populations. Within the wider context of food security, such programmes can be designed to rehabilitate agricultural infrastructure, such as the food storage warehouse at the Agriculture Directorate in Dhuluiyah District, or to establish new agricultural facilities such as the construction of the irrigation sub-canal in Yathrib District, which not only increased food production for the region but also resolved a long-standing local conflict, thus providing one of the clearest examples of the positive role that agriculture can play in post-conflict and stabilisation processes and even for the objective of peacebuilding. The peacebuilding dimension is also highlighted in the recent work of McAllister and Wright [49] in rural Zimbabwe, as they suggest in this fragile context that agroecology as a form of sustainable agriculture may be people-centred, rural peacebuilding praxis and that the social aspects of farming have the ability to re-forge relationships and bridge divisions.

\section{Conclusion}

Arguably, one of the main benefits from developing the concept of "Stabilisation Agriculture" is the repositioning it brings by elevating agriculture as a critical response tool in post-conflict and stabilisation settings. The importance of this has been demonstrated in the case studies from Afghanistan and Iraq and is also evident and being playedout each day in the contemporary fragile states of Libya, Nigeria, Somalia and Yemen, where conflict is creating havoc on local agricultural production, creating cycles of food shortages that in many case lead to famine and mass forced migration. Perhaps it is this agriculture, food security and conflict nexus that forms the crux of Stabilisation Agriculture, or as described in the first promotional material "Exploring sustainable agriculture and institutional engagement in 'stabilisation' regions" ([I], p. I). Certainly, the Stabilisation Agriculture case studies from Afghanistan and Iraq have focussed on this nexus rather than the broader definitional components of re-establishing agriculture after natural disasters, the sustainable management of abiotic and biotic stresses in agriculture and integrating and mainstreaming agroecology through programmes, policies and institutions, for disaster risk reduction (DRR). In some sense, these broader components can be simply viewed as "sustainable agriculture", such as agroecology or agroforestry, but in a disaster risk management context or within a disaster risk reduction approach, whereas post-conflict stabilisation in this context is clearly not relevant. And whilst some may argue that "stabilisation" also applies to bio-physical earth processes, it should be noted that these are already included by default in sustainable agriculture. Therefore, in conclusion, the authors rather reiterate and emphasise the important and positive role that agriculture can play in post-conflict and stabilisation settings, particularly in those post-conflict areas also affected by the climate crisis, and thus offer a redefined definition:

\begin{abstract}
Stabilisation Agriculture can be defined as any agricultural activity undertaken as an initial response in conflict and fragile settings to protect primary food production systems, address fragility, reduce conflict, and prepare an integrated transition for environmental protection, food security, peacebuilding and longer term stability.
\end{abstract}

Linked to this definition, it should also be reiterated that Stabilisation Agriculture is not a return to the past or to the pre-conflict conditions. Rather the opposite, as change is embraced to improve on the previous farming systems through the introduction of regenerative and ecological approaches that build resilience and that are climate smart, for example, through the adoption of agroecology 
or agroforestry-based systems. It is from these multiple and dynamic perspectives that the authors call for Stabilisation Agriculture to be mainstreamed into stabilisation theory at the policy level and into stabilisation and post-conflict programmes at the operational level.To facilitate this process, increased funding and support at the two strategic levels of policy and operations will be required, to create an enabling environment that allows all the benefits of Stabilisation Agriculture to flourish, thus addressing food security and peacebuilding in a range of conflict, post-conflict and stabilisation settings, particularly in geographical areas that may also be subject to the dynamic pressures resulting from the climate crisis.

\section{References}

1. CAFS. Theme: stabilisation agriculture. Case studies (A4 promotional sheet). Coventry: Centre for Agroecology and Food Security (CAFS), Coventry University; 2011.

2. Simon D, Adam-Bradford A. Hybrid planning in the peri-urban interface: applying archaeology and contemporary dynamics for more sustainable, resilient cities. In: Maheshwari B, Singh VP, Thoradeniya B, editors. Balanced urban development: options and strategies for liveable cities. London: Springer; 2016. p. 57-83.

3. Rohwerder B. Supporting agriculture in protracted crises and rebuilding agriculture after conflict and disasters. K4D helpdesk report. Brighton, UK: Institute of Development Studies; 2017. p. 31.

4. UNDP. Stabilizing countries in crisis. 2019. Available from: URL: https://stories.undp.org/stabilizing-countries-in-crisis [accessed: 05 June 2020].

5. Stabilisation Unit. The UK government's approach to stabilisation: a guide for policy makers and practitioners. London: Stabilisation Unit, UK Government; 2018.

6. USAID. The bureau for conflict prevention and stabilisation (CPS). Washington (DC): United States Agency for International Development; 2018. p. 2. Available from: URL: https://www.usaid.gov/sites/default/files/documents/1868/ Fact_Sheet_The_Bureau_for_Conflict_Prevention_and_ Stabilization_CPS. .pdf [accessed: 05 June 2020].

7. The Prime Minister's Office, The Ministry of Foreign Affairs, The Ministry of Defence, The Ministry of Justice. Denmark's integrated peace and stabilisation engagements 2018: the whole-of-government steering committee. The peace and stabilisation fund: annual report 2018. Available from: URL: https://www.fmn.dk/nyheder/Documents/DenmarksIntegrated-Peace-and-Stabilisation-Engagements-2018.pdf [accessed: 05 June 2020].

8. Özerdem A, Roberts R, editors. Challenging post-conflict environments: sustainable agriculture. Surrey, UK: Ashgate; 2012.

9. Milich L. Explicitly licit: stemming the sand tide in Kohsan District, Herat Province, Afghanistan. In: Özerdem A, Roberts $\mathrm{R}$, editors. Challenging post-conflict environments: sustainable agriculture. Surrey, UK: Ashgate; 2012. p. 161-74.

10. Cáceres SB, Ear S. Cambodia: the challenge of adding value to agriculture after conflict. In: Özerdem A, Roberts R, editors. Challenging post-conflict environments: sustainable agriculture. Surrey, UK: Ashgate; 2012. p. 133-46.
11. Stoll $S$. Women in Aceh: conflict and changing agricultural roles. In: Özerdem A, Roberts R, editors. Challenging post-conflict environments: sustainable agriculture. Surrey, UK: Ashgate; 2012. p. 89-100.

12. Roberts $R$. The legacy of war: unexploded cluster munitions in Southern Lebanon. In: Özerdem A, Roberts R, editors. Challenging post-conflict environments: sustainable agriculture. Surrey, UK: Ashgate; 2012. p. 77-87.

13. Neupane G, Slade R. How conflict affected agriculture in Nepal. In: Özerdem A, Roberts R, editors. Challenging post-conflict environments: sustainable agriculture. Surrey, UK: Ashgate; 2012. p. 65-75.

14. Wright J, Weerakoon L. Taking an agroecological approach to recovery: is it worth it and is it possible? In: Özerdem A, Roberts R, editors. Challenging post-conflict environments: sustainable agriculture. Surrey, UK: Ashgate; 2012. p. 103-15.

15. Asenso-Okyere K, Kebede SW. The effects of civil war on agricultural development and rural livelihood in Sierra Leone. In: Özerdem A, Roberts R, editors. Challenging post-conflict environments: sustainable agriculture. Surrey, UK: Ashgate; 2012. p. 49-63.

16. Bolten $\mathrm{C}$. The only way to produce food is to cooperate and reconcile? Failures of cooperative agriculture in post-war Sierra Leone. In: Özerdem A, Roberts R, editors. Challenging post-conflict environments: sustainable agriculture. Surrey, UK: Ashgate; 2012. p. 237-48.

17. Maconachie R. Youth, associations and urban food security in post-war Sierra Leone. In: Özerdem A, Roberts R, editors. Challenging post-conflict environments: sustainable agriculture. Surrey, UK: Ashgate; 2012. p. 220-35.

18. Morgan L, Peacocke B. Practical action in North Darfur. In: Özerdem A, Roberts R, editors. Challenging post-conflict environments: sustainable agriculture. Surrey, UK: Ashgate; 2012. p. 189-202.

19. Tidball KG, Krasny ME, editors. Greening in the red zone: disaster, resilience and community greening. New York, USA: Springer; 2014a.

20. Tidball KG, Krasny ME. Introduction: greening in the red zone. In: Tidball KG, Krasny ME, editors. Greening in the red zone: disaster, resilience and community greening. New York, USA: Springer; 2014b. p. 3-24.

21. Smallwood PD. The risks of greening in the red zone: creating Afghanistan's first national park in the midst of conflict. In: Tidball KG, Krasny ME, editors. Greening in the red zone: disaster, resilience and community greening. New York, USA: Springer; 2014. p. 297-303.

22. Thompson S. 8,000 trees: a refuge from ruins. In: Tidball KG Krasny ME, editors. Greening in the red zone: disaster, resilience and community greening. New York, USA: Springer; 2014. p. 125-8.

23. Laćan I, Mcbride JR. Destruction and replanting of the urban forest of Sarajevo, Bosnia and Herzegovina. In: Tidball KG, Krasny ME, editors. Greening in the red zone: disaster, resilience and community greening. New York, USA: Springer; 2014. p. 305-20.

24. Moore EA. Reforestation activities at a chadian refugee camp in Northern Cameroon. In: Tidball KG, Krasny ME, editors. Greening in the red zone: disaster, resilience and community greening. New York, USA: Springer; 2014. p. 411-5.

25. Cheng S, McBride JR. Restoration of the urban forests of Tokyo and Hiroshima following World War II. In: Tidball KG, 
Krasny ME, editors. Greening in the red zone: disaster, resilience and community greening. New York: Springer; 2014. p. 225-48.

26. Holder C. Growing hope: how urban gardens are empowering war-affected Liberians and harvesting a new generation of city farmers. In: Tidball KG, Krasny ME, editors. Greening in the red zone: disaster, resilience and community greening. New York, USA: Springer; 2014. p. 417-28.

27. CAWR. Stabilisation agriculture unit (A4 trifold promotional brochure). Coventry: Centre for Agroecology, Water and Resilience (CAWR), Coventry University; 2016.

28. Adam-Bradford A, Hoekstra F, van Veenhuizen R. Editorial - linking relief, rehabilitation and development, a role for urban agriculture? Urban Agriculture Magazine 2009;21:3-10.

29. WTsadik M. Enhancing household food security in refugee camps in Ethiopia. Urban Agriculture Magazine 2009;21:16-7.

30. Adam-Bradford A, Osman, M. Tsunami aftermath: development of an indigenous home garden in Banda Aceh. Urban Agriculture Magazine 2009;21:29-30.

31. Ormizyari GB. The role of urban agriculture in Kirkuk, Iraq. Urban Agriculture Magazine 2009;21:24-5.

32. Dalahmeh S, Assayed A. Health risk assessment of children exposed to greywater in jerash refugee camp in Jordan. Urban Agriculture Magazine 2009;21:41-2.

33. Corbett M. Multi-storey gardens to support food security. Urban Agriculture Magazine 2009;21:34-5.

34. Jansen BJ. The accidental city: urbanisation in an East-African refugee camp. Urban Agriculture Magazine 2009;21:11-2.

35. Kortu T. Urban agriculture in and around Monrovia, Liberia. Urban Agriculture Magazine 2009;21:22-3.

36. Kanu S, Tengbe P, Winnebah TRA, Konneh P. Promoting urban agriculture in post-conflict greater Freetown area, Sierra Leone. Urban Agriculture Magazine 2009;21:19-21.

37. Radice HW, Velly D. Farming in bags: micro-gardening in northern Uganda. Urban Agriculture Magazine 2009;21:36-7.

38. van Rooij A, Liem L. From dependence to self-reliance: experiences from northern Uganda. Urban Agriculture Magazine 2009;21:13-5.

39. Toriro $P$. The impact of the economic meltdown on urban agriculture in Harare. Urban Agriculture Magazine 2009;21:26-7.

40. Adam-Bradford A, Tomkins M, Perkins C, van Veenhuizen R, Binego L, Hunt S, et al. Transforming land, transforming lives: greening innovation and urban agriculture in the context of forced displacement. 2nd ed. Dallas, USA: Lemon Tree Trust; 2017. p. 40

41. Millican J, Perkins C, Adam-Bradford A. Gardening in displacement: the benefits of cultivating in crisis. Journal of Refugee Studies 2018;32(3):46-48. doi: 10.1093/ jrs/fey033
42. Perkins C, Adam-Bradford A, Tomkins M. Thriving spaces: the benefits and challenges of incorporating urban agriculture into refugee camp infrastructure. Forced Migration Review 2017;55:46-8.

43. Adam-Bradford A. Agroforestry for refugee camps. Agriculture for Development 2016;28:29-31.

44. Tomkins M, Yousef S, Adam-Bradford A, Perkins C, Grosrenaud E, McTough $\mathrm{M}$, et al. Cultivating refuge: the role of urban agriculture amongst refugees and forced migrants in the Kurdistan region of Iraq. International Journal of Design and Nature and Ecodynamics 2019;14(2):103-18.

45. Charlesworth SM, Winter K, Adam-Bradford A, Mezue M, McTough $M$, Warwick $F$, et al. Sustainable drainage in challenging environments. New Water Policy and Practice Journal 2017;4(1):31-41.

46. Borra $B$, van Veenhuizen $R$, Schut $M$, Adam-Bradford $A$. Linking urban framing and urban planning in times of crisis. Urban Agriculture Magazine 2016;31:38-40.

47. CAWR. Stabilisation agriculture (A4 trifold promotiona brochure). Coventry: Centre for Agroecology, Water and Resilience (CAWR), Coventry University; 2019a.

48. CAWR. Stabilisation agriculture (A5 promotional brochure). Coventry: Centre for Agroecology, Water and Resilience (CAWR), Coventry University; 2019b. p. 8.

49. McAllister G, Wright J. Agroecology as a practice-based tool for peacebuilding in fragile environments? Three stories from rural Zimbabwe. Sustainability 2019;11(3):790-811.

50. UNDP. Stabilization in Tikrit. Funding facility for immediate stabilization. Iraq: United Nations Development Programme; 2016. p. 2. Available from: URL: http://www.iq.undp.org/ content/iraq/en/home/ourwork/Stabilization/our-stories/ stabilization-in-tikrit/ [accessed: 06 November 2019].

51. Neurink J. Tikrit university brings life back to Saddam's hometown. Erbil, Iraq: Rudaw; 2016. Available from: URL: http://www.rudaw.net/english/middleeast/iraq/060620161 [accessed: 05 June 2020].

52. HRF. Cash for work for stabilisation agriculture activities in Al Hajaj, Salah Al-Din governorate. Final project report. Iraq: Human Relief Foundation; 2016a. p. 14.

53. HRF. Stabilisation agriculture cash for work project in Dhuluiyah, Salah Al-Din governorate. Final project report. Iraq: Human Relief Foundation; 2016b. p. 15.

54. HRF. Stabilisation agriculture cash for work project in Yathrib, Salah Al-Din governorate. Final project report. Iraq: Human Relief Foundation; 2017. p. 22.

55. Adam-Bradford A. Review of Warah, R. (2014) War crimes: how warlords, politicians, foreign governments and aid agencies conspired to create a failed state in Somalia. AuthorHouse, Bloomington, Indiana, USA. Land Degradation and Development 2014;25:2. doi: 10.1002/ldr.2312

56. Rembold F, Oduori SM, Gadain H, Toselli P. Mapping charcoal driven forest degradation during the main period of Al Shabaab control in southern Somalia. Energy for Sustainable Development 2013;17:510-4. 